\title{
Post-traumatic stress disorder and association with low birth weight in displaced population following conflict in Malakand division, Pakistan: a case control study
}

\author{
Haroon Ur Rashid ${ }^{1}$, Muhammad Naseem Khan ${ }^{1,2^{*}}$, Ayesha Imtiaz', Naeem Ullah ${ }^{3}$, Mukesh Dherani ${ }^{2}$ and
} Atif Rahman 2,4

\begin{abstract}
Background: The northern part of the province of Khyber Pakhtunkhwa in Pakistan experienced armed conflict since September 2007 till the autumn of 2011. Conflict involved widespread insurgency activity and military intervention including in 2009 internally displacing the 2.5 million people of the valley of Swat to live in camps, with relatives, or in rented accommodation across the region for approximately 4 months. It was during this period the current study was conducted to determine whether Post-Traumatic Stress Disorder in pregnant women was independently associated with Low Birth Weight (LBW) in an area affected by conflict and militancy.
\end{abstract}

Methods: A case control study was conducted in tertiary care hospitals of district Peshawar, Khyber Pakhtunkhwa. Two hundred twenty-five cases (neonates with birth weight $<2.5 \mathrm{~kg}$ ) and 225 controls (neonates with birth weight of $>2.5$ $\mathrm{kg}$ ) were enrolled within $24 \mathrm{~h}$ of delivery. Post-Traumatic Stress Disorder was assessed through the MINI Neuropsychiatric Interview 5.0, a validated questionnaire along with the birth weight of the newborn. Maternal anthropometry, anemia and other sociodemographic details were also obtained during data collection. Data was analyzed using statistical package (STATA version 14). Logistic regression analysis of the association between LBW and all variables collected with a $p$-value of $<0.25$ on uni-variate analysis were entered.

Results: A total of 450 newborn and mother pairs participated in the study with 225 cases and 225 controls. On univariate analysis factors significantly associated with LBW include: less than 5 years of paternal schooling and PTSD. On logistic regression, PTSD was independently associated with low birth weight in the presence of other factors like maternal/paternal schooling, gravida, history of preterm, BMI of the mother and maternal anemia.

Conclusion: PTSD was found to be independently associated with LBW. In light of the current findings and other similar literature, intervention programs should be considered for pregnant women exposed to traumatic events.

Keywords: Low birth weight, Post traumatic stress disorder, Pakistan, Conflict, Pregnancy outcome

\footnotetext{
* Correspondence: drnasim@msn.com

'Institute of Public Health \& Social Sciences (IPH\&SS), Khyber Medical

University, Phase V, Hayatabad, Peshawar, Pakistan

${ }^{2}$ Department of Psychological Medicine, University of Liverpool, Liverpool, UK

Full list of author information is available at the end of the article
}

C C The Author(s). 2020 Open Access This article is licensed under a Creative Commons Attribution 4.0 International License, which permits use, sharing, adaptation, distribution and reproduction in any medium or format, as long as you give appropriate credit to the original author(s) and the source, provide a link to the Creative Commons licence, and indicate if changes were made. The images or other third party material in this article are included in the article's Creative Commons licence, unless indicated otherwise in a credit line to the material. If material is not included in the article's Creative Commons licence and your intended use is not permitted by statutory regulation or exceeds the permitted use, you will need to obtain permission directly from the copyright holder. To view a copy of this licence, visit http://creativecommons.org/licenses/by/4.0/. The Creative Commons Public Domain Dedication waiver (http://creativecommons.org/publicdomain/zero/1.0/) applies to the data made available in this article, unless otherwise stated in a credit line to the data. 


\section{Background}

There is a gradual rise in natural and man-made disasters in the past few decades, with a global estimates of the Internally Displaced Persons (IDPs) resulting from these conflicts since 1990 to 2009 exceeding 23 million. Alarmingly around half of these numbers have occurred in the Eastern Mediterranean Region (EMR) of the World Health Organization (WHO) which includes Pakistan [1, 2]. Majority of IDPs were exposed to dreadful conditions and violations of their basic human rights including the rights to health of mothers and children $[2,3]$. The prevalence of common mental disorders in the conflict affected population was 22.1\% [95\% CI 18.8-25.7] while, that of PostTraumatic Stress Disorder (PTSD) was 15.3\% (95\% CI [9.9-23.5] [4]. PTSD occurs in about $8 \%$ of pregnant women as reported in a study from the US [5], with the rate as high as $42 \%$ for displaced/migrating women [6]. Maternal exposure to stressful situations during pregnancy may have effects on their pregnancy, fetal development and birth outcomes which might result from the maternal endocrine and immune system response to these stressful stimuli $[7,8]$. Research has found associations between adverse pregnancy and birth outcomes and higher risk of morbidity and mortality of the newborn, both in the short and long term [9-11]. However there are mixed results regarding the impact of stress-related illness in pregnancy and preterm or Low Birth Weight (LBW) [12-15]. Apart from these direct effects, the women experiencing stressful conditions during pregnancy are more likely to engage in poor health behaviours including smoking [16], alcohol and drug use [17], and inadequate care utilization [18], all of which may lead to adverse pregnancy outcomes.

LBW baby is defined by the international statistical classification of diseases as a live newborn with a birth weight less than $2500 \mathrm{~g}$ regardless of gestational age [19]. LBW mainly results from prematurity (birth before 37 completed weeks of gestation), or intrauterine growth restrictionIUGR (birth weight $<2.5 \mathrm{~kg}$ and gestational age $>37$ weeks) or both. Reducing the rates of LBW is a major public health concern as it is estimated that around the world about 30 million babies are born with LBW each year and a quarter of them face severe short and long-term health consequences [20].

The northern part (districts of Swat, Dir and Buner) of Pakistan was a nexus of conflict and militancy between the Taliban and the security forces since July, 2008, resulting in a large scale displacement of the local population. Around 2 million had been registered to be displaced from the region. Only $20 \%$ of the displaced were living in 23 camps established by the Pakistan government, the rest were with relatives, rented accommodation, within family homes, in schools, mosques and other community buildings [21]. Most of the displaced people have targeted bigger cities of the province like,
Peshawar, Nowshera and Mardan. It was during this context the present research was planned and conducted. The objective of the current research was to determine whether Post-Traumatic Stress Disorder (PTSD) is independently associated with increased risk of LBW baby. The conflict situation was a natural context to determine this association as most of the displaced persons were living in the major city of Peshawar.

\section{Methods}

This case control study was conducted in three tertiary care hospitals of district Peshawar (Post Graduate Medical Institute Lady Reading Hospital, Khyber Teaching Hospital and Hayat Abad Medical Complex). These are tertiary level referral hospitals for the entire province and it was forecasted that most of the displaced people will avail services in these facilities. The total duration of the study was 4 months, from April 20th to July 3rd, 2009. The study population were single live newborns of 24 or more weeks of gestation and their mothers delivered at or admitted within $24 \mathrm{~h}$ of birth at the hospital maternity wards of the three tertiary care hospitals of Peshawar. Newborn with recognizable congenital anomalies, twin pregnancy, born to mothers whom labor was induced for medical complications or with maternal history of cervical incompetence were excluded. Mothers with known mental health problems or any other serious medical condition were excluded from the study. Cases were newborn mother pairs with the newborn weighing less than $2.5 \mathrm{~kg}$ delivered or admitted within $24 \mathrm{~h}$ of birth in the above mentioned hospital maternity wards. Similarly, controls were newborn mother pairs with the newborn weighing more than or equal to $2.5 \mathrm{~kg}$ delivered or admitted within $24 \mathrm{~h}$ of birth. Cases and controls were enrolled on 1:1 ratio. The controls were selected from the same maternity ward at the same time of the inclusion of the case by random sampling among the women with normal birth weight i.e. $2.5 \mathrm{~kg}$ or more.

To determine the study objective of finding the association between the LBW and the exposure to PTSD, the sample size was estimated based on the following assumptions: an alpha of 0.01 , power of $90 \%$, and assuming a prevalence of PTSD in the population at $10 \%$, ratio of cases vs controls of $1: 1$, and an odds ratio of 3 as a measure of clinical significance. Using OpenEpi version 3.01 [22] a sample size of 404 was estimated i.e. 202 cases and 202 controls. Assuming a non-response rate of $10 \%$ for refusals, 450 sample size was determined with 225 cases and 225 controls.

\section{Instrument and procedures MINI neuropsychiatric interview}

For the diagnosis of current PTSD the MINI Neuropsychiatric Interview 5.0, a validated questionnaire that 
uses DSM-IV criteria was administered [23]. Studies have shown that the MINI Neuropsychiatric Interview 5.0 is a valid and reliable diagnostic tool used in epidemiological studies targeting pregnant women [24, 25]. The questionnaire was administered by trained medical officers in the respective hospitals. For a diagnosis of PTSD the subject was required to confirm experience of an "unusually traumatic or stressful event", re-experiencing the event over the last month and at least 3 of the following: avoidance, amnesia, decreased interest in activities, detachment, numbing, foreshortened future, and at least 2 of the following: trouble sleeping, irritability, difficulty concentrating, nervousness, and feeling easily startled for at least "several days". Lastly, the subject had to indicate whether the above problems had significantly interfered with the daily work or social activities or caused significant distress.

\section{Birth weight}

Birth weight of the newborn was measured by weighing the infant with minimum clothing on and recording the weight to the nearest $0.1 \mathrm{~kg}$, by the trained medical officers. The standard cut-off for LBW in newborns was used i.e. $2.5 \mathrm{~kg}$ or less [26].

\section{Maternal anthropometry and Anemia}

Women's height and weight measurements were recorded from the clinical records. Body Mass Index (BMI) calculations were later done during analysis. BMI was calculated using the standard as weight in kilogram divided by height in meter square classified according to WHO criteria as underweight $(<18.5)$, normal $(18.5-$ 24.9), overweight (25-29.9) and obese (>30) [27]. Likewise, maternal anemia was measured from clinical records and was categorized as anemia with hemoglobin level less than $11 \mathrm{~g} / \mathrm{dl}$ [28].

\section{Socio-demographic characteristics}

Data was also collected regarding the gender of the newborn, maternal age, maternal and paternal schooling, household income, rural/urban residence, Gravida, interpregnancy interval, and previous history of preterm births. Maternal age was participant reported at the time of interview. Maternal and paternal schooling were also recorded and was assessed through formal years of schooling and later categorized as less than 5 years and more than 5 years for analysis as the overall rates of literacy was very low in the study participants. Similarly, household income was categorized as less than or more than Rs. 10,000/month for analysis. Gravidity was defined as the total number of pregnancies including live births, still births and abortions and categorized as primigravida (first pregnancy), 2-3 Gravida (2-3 pregnancies) and 4 or more Gravida ( $\geq 4$ pregnancies). Interpregnancy interval was defined as duration between conception for index pregnancy and the preceding delivery, abortion or stillbirth and was also self-reported by the mother.

The data collection was regularly supervised and monitored by the Principal Investigator (PI). The filled questionnaires by the data collection team were checked by the PI (HR) daily at the end of the day for their completeness. Data were coded and entered into the SPSS version 23 and analyzed using statistical package (STATA version 14). Descriptive analysis included frequencies and percentages for all the variables. For univariate analysis of the association between LBW and all other factors Chi square test (Fisher's two-sided exact test was used if numbers in the cells $<5$ ) was used. Associations were considered significant at $5 \%$. Logistic regression analysis of the association between LBW and all those variables with a $p$-value of $<0.25$ on uni-variate analysis were entered in the logistic regression model.

The study was approved by the ethical committee of Health Services Academy, Islamabad. Informed written consent obtained from study participants following explanation of the study aims and objectives. In case of illiterate women, the information was verbally explained to them in the local language and consent taken thereafter. The right to withdraw from the study was reinforced to all the participants throughout the study conduct. All information obtained in the study was kept confidential with access to personal information available only to the study lead (HR). Cases of severe distress and other health concerns requiring immediate treatment were referred to the concern department accordingly.

\section{Results}

A total of 450 newborn and mother pairs participated in the study with 225 cases (LBW mother pairs) and 225 controls (normal weight babies and mother pairs). Table 1 shows the association of socio-demographic and other factors with LBW (cases) and normal weight babies (controls). Factors significantly associated with LBW include: less than 5 years of paternal schooling $(p=0.017)$ and PTSD $(p<0.001)$. All other factors were not found to be statistically significant and were; sex of the newborn child, maternal age, maternal schooling, monthly family income, rural/urban residence, Gravida, inter-pregnancy interval, previous history of preterm birth, maternal BMI and maternal anemia.

Table 2 shows the uni-variate logistic regression analysis between the cases and controls and all the sociodemographic and other factors.. As is shown in the table $48 \%$ of the fathers of the cases had less than 5 years of schooling, compared to $36.9 \%$ of the controls; showing significant association with LBW: OR $=1.58(95 \% \mathrm{CI}$ 1.08 to 2.30). Around one third (31.6\%) of the mother of the cases were diagnosed with PTSD, compared to only 
Table 1 Factors among cases and controls

\begin{tabular}{|c|c|c|c|}
\hline Variables/Factors & $\begin{array}{l}\text { Cases (LBW) } \\
\boldsymbol{N}=225 \\
\mathrm{n}(\%)\end{array}$ & $\begin{array}{l}\text { Controls (NBW) } \\
\boldsymbol{N}=225 \\
\mathrm{n}(\%)\end{array}$ & $P$ value \\
\hline Male Neonate & $131(58.2)$ & $126(56.0)$ & 0.634 \\
\hline \multicolumn{4}{|l|}{ Maternal Age } \\
\hline $20-35$ yrs. & $172(76.4)$ & $178(79.1)$ & \multirow[t]{3}{*}{0.606} \\
\hline$<20$ years & $30(13.3)$ & $30(13.3)$ & \\
\hline$>35$ years & $23(10.2)$ & $17(7.6)$ & \\
\hline$<5$ years of Maternal Schooling & $150(66.7)$ & $163(72.4)$ & 0.183 \\
\hline$<5$ years of Paternal Schooling & $108(48.0)$ & $83(36.9)$ & 0.017 \\
\hline < 10,000/Monthly Income (PKR) & $157(69.8)$ & $167(74.2)$ & 0.294 \\
\hline Rural Residence & $161(71.6)$ & $170(75.6)$ & 0.336 \\
\hline Primigravida & $58(25.8)$ & $76(33.8)$ & \multirow[t]{3}{*}{0.179} \\
\hline 2-3 Gravida & $67(29.8)$ & $60(26.6)$ & \\
\hline 4 or more Gravida & $100(44.4)$ & 89 (39.6) & \\
\hline$<2$ years Inter pregnancy Interval ${ }^{a}$ & $109(65.3)$ & $87(58.4)$ & 0.208 \\
\hline History of preterm birth & $38(16.9)$ & $25(11.1)$ & 0.077 \\
\hline Normal (BMI 18.5-24.9) & $181(80.4)$ & $183(81.3)$ & \multirow[t]{3}{*}{0.746} \\
\hline Under weight (BMI < 18.5) & $26(11.6)$ & $28(12.4)$ & \\
\hline Over weight (BMI 25-29.9) & $18(8)$ & $14(6.2)$ & \\
\hline Maternal Anemia & $111(49.3)$ & $107(47.6)$ & 0.706 \\
\hline PTSD & 71 (31.6) & $13(5.8)$ & $<0.001$ \\
\hline
\end{tabular}

aprimigravida excluded from analysis

$5.8 \%$ of the controls: $\mathrm{OR}=7.52$ (95\% CI 4.02 to 14.07 ). The association between LBW and all other variables was not found to be statistically significant.

To study the association of combined effects of all these variables on the risk of being a LBW, a logistic regression model was created. In this model, only those variables that had a $p$ value of $<0.25$ in the uni-variate regression model were included in the analysis. These include maternal education, paternal education, Gravida status, inter-pregnancy interval, history of preterm birth and PTSD. The logistic regression model (Table 3) found that PTSD was significantly associated with LBW in the presence of other variables i.e. maternal education, paternal education, Gravida status, inter-pregnancy interval and history of preterm birth. Mothers of LBW babies were 7.52 times more likely to have been exposed to PTSD independent of other risk factors/variables.

\section{Discussion}

This study found that PTSD exposure during pregnancy is independently associated with the risk of LBW in the presence of other risk factors like maternal education, paternal education, Gravida status, inter-pregnancy interval and history of preterm birth. The study was conducted in a context where active conflict was ongoing in the northern part of Khyber Pakhtunkhwa and the population was displaced to the major cities. Therefore, the current study was quite unique as it found association in real world with active conflict affected participants.

The key finding of the current study was that PTSD was independently associated with LBW. Similar results have been shown in literature from other areas with conflict or some other terror attacks or generalized stress or distress. In a prospective cohort study conducted in Sau Palo Brazil, 865 pregnant women who attended antenatal care between September 1997 and August 2000 were assessed for stress and distress by interview during the three trimesters of pregnancy. Maternal distress was associated with LBW in the second trimester and with prematurity in the third trimester in the presence of other risk factors. The prevalence of stress and distress in the different trimesters of pregnancy varied from 22.1 to $52.9 \%$ [29]. Similarly a cohort study by Seng et al. identified PTSD as a strong predictor of poor birth outcome in terms of LBW and prematurity [30]. Similarly another cohort study showed same results, as women with PTSD (PTSD assessed with MINI neuropsychiatric interview as in the current study) were at greater risk of delivering preterm babies compared those who were not diagnosed with PTSD [14]. The results were not statistically significant as the cohort had very small numbers of 
Table 2 Factors and association with LBW among cases and controls

\begin{tabular}{|c|c|c|c|c|c|}
\hline Variables/Factors & $\begin{array}{l}\text { Cases (LBW) } \\
\boldsymbol{N}=225 \\
\mathrm{n}(\%)\end{array}$ & $\begin{array}{l}\text { Controls (NBW) } \\
\boldsymbol{N}=225 \\
\mathrm{n}(\%)\end{array}$ & OR & $95 \% \mathrm{Cl}$ & $P$ value \\
\hline Male Neonate & $131(58.2)$ & $126(56.0)$ & 1.09 & 0.75 to 1.59 & 0.634 \\
\hline \multicolumn{6}{|l|}{ Maternal Age } \\
\hline $20-35$ yrs. & $172(76.4)$ & $178(79.1)$ & \multicolumn{3}{|c|}{ Reference category } \\
\hline$<20$ years & $30(13.3)$ & $30(13.3)$ & 1.03 & 0.60 to 1.79 & 0.902 \\
\hline$>35$ years & $23(10.2)$ & $17(7.6)$ & 1.40 & 0.72 to 2.71 & 0.318 \\
\hline$<5$ years of Maternal Schooling & $150(66.7)$ & $163(72.4)$ & 0.76 & 0.51 to 1.14 & 0.183 \\
\hline$<5$ years of Paternal Schooling & $108(48.0)$ & $83(36.9)$ & 1.58 & 1.08 to 2.30 & 0.017 \\
\hline$<$ 10,000/Monthly Income (PKR) & $157(69.8)$ & $167(74.2)$ & 0.80 & 0.53 to 1.21 & 0.294 \\
\hline Rural Residence & $161(71.6)$ & $170(75.6)$ & 0.81 & 0.53 to 1.24 & 0.336 \\
\hline \multicolumn{6}{|l|}{ Gravidity } \\
\hline Primigravida & $58(25.8)$ & $76(33.8)$ & \multicolumn{3}{|c|}{ Reference category } \\
\hline 2-3 Gravida & $67(29.8)$ & $60(26.6)$ & 1.46 & 0.90 to 2.38 & 0.126 \\
\hline 4 or more Gravida & $100(44.4)$ & 89 (39.6) & 1.47 & 0.94 to 2.30 & 0.089 \\
\hline$<2$ years Inter pregnancy Interval* & $109(65.3)$ & $87(58.4)$ & 1.34 & 0.85 to 2.11 & 0.209 \\
\hline History of preterm birth & $38(16.9)$ & $25(11.1)$ & 1.63 & 0.94 to 2.80 & 0.079 \\
\hline \multicolumn{6}{|l|}{ Maternal Body Mass Index } \\
\hline Normal (BMI 18.5-24.9) & $181(80.4)$ & $183(81.3)$ & \multicolumn{3}{|c|}{ Reference category } \\
\hline Under weight $(\mathrm{BMI}<18.5)$ & $26(11.6)$ & $28(12.4)$ & 0.94 & 0.53 to 1.66 & 0.829 \\
\hline Over weight (BMI 25-29.9) & $18(8)$ & $14(6.2)$ & 1.30 & 0.63 to 2.69 & 0.480 \\
\hline Maternal Anemia & $111(49.3)$ & $107(47.6)$ & 1.07 & 0.74 to 1.55 & 0.706 \\
\hline PTSD & $71(31.6)$ & $13(5.8)$ & 7.52 & 4.02 to 14.07 & $<0.001$ \\
\hline
\end{tabular}

PTSD and hence the sample was underpowered. On the other hand, minor depressive disorder was significantly associated with LBW [14].

Literature has found some contrasting results as well. A study was conducted in USA to see the effect of extreme trauma on the birth outcomes of women highly exposed to the World Trade Center on 11 September 2001 [13]. The study did not found any significant association between the terror attack and adverse perinatal outcomes. The difference was that they enrolled women mostly in their first trimester on $11^{\text {th }}$ September and the sample size was small as compared to the current study. Apart from that the event was a onetime exposure and was an acute one. While in the current study it was a chronic exposure to the traumatic and terror acts and these women were displaced from their houses and were living in camps, with relatives or rented accommodation. Research has indicated that persistent exposure to stressful stimuli for long periods make the perinatal outcomes worse. A further explanation could be that most of their sample was in the first trimester which as discussed in the other study [29] above did not have any association with poor pregnancy outcome.

Maternal age and association with LBW was not found to be statistically significant when compared for mothers below 20 and above 35 years of age. Similar findings were observed in a case control study in the present context where no association was observed between LBW and teenage pregnancy [31]. However, a cohort study revealed higher risk of preterm and LBW in adolescent (<18 years) mothers [32]. Furthermore, interpregnancy interval has been shown to be associated with LBW $[33,34]$. In the present study again no such association was observed possibly as we excluded primigravida from this analysis and the remaining sample may be under powered, although the odds were more for the LBW mothers. Low pre-pregnancy Body Mass Index (BMI) is one of the strongest predictors of adverse pregnancy outcomes such as preterm birth and fetal growth retardation. BMI of $<18.5$ was found to be significantly associated with LBW in a study [35]. Similarly, mothers who were underweight, were 3.4 times more likely to give birth to an IUGR baby [36]. However, in the current study BMI (both high and low) was not found to be statistically associated with LBW. The main reason could be that these measures were not recorded for the prepregnancy time and were only available at the time of data collection during the hospital.

Others factors found to be associated with LBW, as reported by previous studies, include pregnancy related 
Table 3 Logistic Regression Analysis

\begin{tabular}{|c|c|c|c|c|}
\hline Variables/Factors & Unadjusted OR & $95 \% \mathrm{Cl}$ & Adjusted OR & $95 \% \mathrm{Cl}$ \\
\hline Male Neonate & 1.09 & 0.75 to 1.59 & - & - \\
\hline \multicolumn{5}{|l|}{ Maternal Age } \\
\hline $20-35$ yrs & Reference category & & & \\
\hline$<20$ years & 1.03 & 0.60 to 1.79 & - & - \\
\hline$>35$ years & 1.40 & 0.72 to 2.71 & - & - \\
\hline$<5$ years of Maternal Schooling & 0.76 & 0.51 to 1.14 & 0.41 & 0.23 to 0.75 \\
\hline$<5$ years of Paternal Schooling & 1.58 & 1.08 to 2.30 & 1.39 & 0.81 to 2.38 \\
\hline < 10,000/Monthly Income (PKR) & 0.80 & 0.53 to 1.21 & - & - \\
\hline Rural Residence & 0.81 & 0.53 to 1.24 & - & - \\
\hline Primigravida & Reference category & & & \\
\hline 2-3 Gravida & 1.46 & 0.90 to 2.38 & - & - \\
\hline 4 or more Gravida & 1.47 & 0.94 to 2.30 & 1.05 & 0.64 to 1.73 \\
\hline$<2$ years Inter pregnancy Interval* & 1.34 & 0.85 to 2.11 & 1.55 & 0.94 to 2.56 \\
\hline History of preterm birth & 1.63 & 0.94 to 2.80 & 1.41 & 0.77 to 2.58 \\
\hline Normal (BMI 18.5-24.9) & Reference category & & & \\
\hline Under weight (BMI < 18.5) & 0.94 & 0.53 to 1.66 & - & - \\
\hline Over weight (BMI 25-29.9) & 1.30 & 0.63 to 2.69 & - & - \\
\hline Maternal Anemia & 1.07 & 0.74 to 1.55 & - & - \\
\hline PTSD & 7.52 & 4.02 to 14.07 & 6.07 & 2.99 to 12.31 \\
\hline
\end{tabular}

complications, acute/chronic infections during pregnancy [37], and lack of antenatal care [37, 38]. Similarly exposure to other stressful events during pregnancy such as natural disasters (earthquakes, hurricane) [39], childhood maltreatment history [30], domestic violence, food insufficiency [40], were also identified as risk factors for LBW. However, investigating those factors was beyond the scope of the current study.

The major strength of the current study was that the data collection was done at a time when most of the districts were exposed to conflict and militancy in the area. Large number of people migrated and were living in camps, with relatives or rented accommodation in district Peshawar. Therefore, the study captured the real occurrence of PTSD and its association with LBW. As data was collected from the three main tertiary care facilities therefore could be generalized with caution. Moreover, the tool used for the main exposure variable of PTSD (MINI Neuropsychiatric Interview 5.0) is a valid and reliable diagnostic tool with high inter-rater and test-retest reliabilities and is considered as a gold standard for psychiatric disorders [25]. The main limitation of the current study was that we used women records for some of the factors like anemia and pre pregnancy BMI, the authenticity of these variables could not be guaranteed. Moreover Genetic, behavioral and environmental factors might be associated with LBW and were not assessed in the current study. Furthermore, a prospective cohort study would be a better design to investigate the current association.

\section{Conclusions}

To conclude PTSD was found to be independently associated with LBW in the displaced population following the conflict in the Malakand division of Pakistan. LBW is a major public health problem as most of the children face short and long-term consequences [20], therefore intervention programs should be considered for pregnant women exposed to traumatic events and further studies are recommended in the local context to evaluate the effectiveness of such interventions. Based on the current study we can infer that stresses during antenatal period negatively influence fetal growth. However, other factors including genetic, behavioral and environmental factors need to be explored.

\section{Abbreviations}

BMI: Body mass index; Cl: Confidence interval; DSM: Diagnostic and statistical manual; EMR: Eastern Mediterranean Region; IDPs: Internally displaced persons; IUGR : Intrauterine growth restriction; Kg: Kilogram; LBW: Low birth weight; OR: Odds ratio; PTSD: Post-traumatic stress disorder; USA : United States of America; WHO: World Health Organization

\section{Acknowledgements}

We are thankful to all the study participants for their time and involvement in the study. We are also very thankful to the team of data collectors and hospital administration. We are extremely thankful to the management of Health Services Academy, Islamabad for the technical and financial support of the study. 


\section{Authors' contributions}

$H R$ and MNK contributed in the conceptualization of the research study. HR conducted field research activities and was involved in the data collection, cleaning and initial analysis. Further analysis was supported by Al, MD NU and $A R$. HR, MNK and Al prepared the first draft, while MD and AR edited and reviewed drafts. The authors read and approved the final manuscript.

\section{Funding}

This study was funded by Health Services Academy, Islamabad. The funding body has no role in the design of the study and collection, analysis, and interpretation of the data and in writing of the manuscript.

\section{Availability of data and materials}

The raw data available upon reasonable request from the corresponding author.

\section{Ethics approval and consent to participate}

The study was approved by the ethical committee of Health Services Academy, Islamabad. Informed written consent obtained from study participants following explanation of the study aims and objectives. All procedures were performed with strict ethical standards.

\section{Consent for publication}

Not applicable.

\section{Competing interests}

The authors declare that they have no competing interests.

\section{Author details}

'Institute of Public Health \& Social Sciences (IPH\&SS), Khyber Medical University, Phase V, Hayatabad, Peshawar, Pakistan. ${ }^{2}$ Department of Psychological Medicine, University of Liverpool, Liverpool, UK. ${ }^{3}$ Saidu Medical College, Swat, Pakistan. ${ }^{4}$ Human Development Research Foundation, Islamabad, Pakistan.

\section{Received: 18 May 2019 Accepted: 25 February 2020}

Published online: 17 March 2020

\section{References}

1. International Displacement Monitoring Center. Global Statistics. IDP estimates (2001-2009). Available from: http://www.internal-displacement. org/database/. [cited 2012 December 24].

2. Leus X, Wallace J, Loretti A. Internally displaced persons. Prehosp Disaster Med. 2001:16(3):116-23.

3. Mkoji G. Civil turmoil in Africa: a potential setback in the fight against diseases. Afr J Health Sci. 1996:3(4):109.

4. Fiona C, Ommeren MV, Flaxman A, Cornett J, Whiteford H, Saxena S. New WHO prevalence estimates of mental disorders in conflict settings: a systematic review and meta-analysis. Lancet. 2019;394(10194):240-8. https:// doi.org/10.1016/SO140-6736(19)30934-1.

5. Yonkers KA, Smith MV, Forray A, Epperson N, Costello D, Lin H, et al. Pregnant women with posttraumatic stress disorder and risk of preterm birth. JAMA Psychiatry. 2014;71(8):897-904. https://doi.org/10.1001/ jamapsychiatry.2014.558.

6. Fellmeth $\mathrm{G}$, Fazel $\mathrm{M}$, Plugge E. Migration and perinatal mental health in women from low- and middle-income countries: a systematic review and meta-analysis. BLOG. 2017:124(5):742-52

7. Field T, Diego M. Cortisol: the culprit prenatal stress variable. Int J Neurosci. 2008;118(8):1181-205.

8. Hobel CJ, Goldstein A, Barrett ES. Psychosocial stress and pregnancy outcome. Clin Obstet Gynecol. 2008;51(2):333-48.

9. Laplante DP, Brunet A, Schmitz N, Ciampi A, King S. Project ice storm: prenatal maternal stress affects cognitive and linguistic functioning in $51 / 2-$ year-old children. J Am Acad Child Adolesc Psychiatry. 2008:47(9):1063-72.

10. Weinstock $M$. The long-term behavioural consequences of prenatal stress. Neurosci Biobehav Rev. 2008;32(6):1073-86.

11. Hernández-Martínez C, Arija V, Balaguer A, Cavallé P, Canals J. Do the emotional states of pregnant women affect neonatal behaviour? Early Hum Dev. 2008;84(11):745-50.
12. Seng JS, Oakley DJ, Sampselle CM, Killion C, Graham-Bermann S, Liberzon I. Posttraumatic stress disorder and pregnancy complications. Obstet Gynecol. 2001;97(1):17-22.

13. Engel SM, Berkowitz GS, Wolff MS, Yehuda R. Psychological trauma associated with the world trade center attacks and its effect on pregnancy outcome. Paediatr Perinat Epidemiol. 2005;19(5):334-41.

14. Rogal SS, Poschman K, Belanger K, Howell HB, Smith MV, Medina J, et al. Effects of posttraumatic stress disorder on pregnancy outcomes. J Affect Disord. 2007;102(1):137-43.

15. Wainstock T, Anteby E, Glasser S, Shoham-Vardi I, Lerner-Geva L. The association between prenatal maternal objective stress, perceived stress, preterm birth and low birthweight. J Matern Fetal Neonatal Med. 2013; 26(10):973-7.

16. Kornfield SL, Moseley M, Appleby D, McMickens CL, Sammel MD, Epperson CN. Post-traumatic symptom reporting and reported cigarette smoking during pregnancy. J Womens Health. 2017;26(6). https://doi.org/10.1089/ jwh.2016.5928.

17. Onah MN, Field S, Heyningen T, Honikman S, et al. Predictors of alcohol and other drug use among pregnant women in a peri-urban South African setting. Int J Ment Health Syst. 2016;10(38). https://doi.org/10.1186/s13033016-0070-x.

18. Bell SA, Seng J. Childhood maltreatment history, posttraumatic relational sequelae, and prenatal care utilization.[internet]. J Obstet Gynecol Neonatal Nurs. 2013;42(4):404-15. https://doi.org/10.1111/1552-6909.12223.

19. World Health Organization. International statistics classification of diseases and related health problems, vol. 2. 10th ed. Geneva: WHO; 1993. Available from: http://apps.who.int/classifications/icd10/browse/2016/en\#/P07.1.

20. Biswas R, Dasgupta A, Sinha R, Chaudhuri R. An epidemiological study of low birth weight newborns in the district of Puruliya, West Bengal. Indian J Public Health. 2008:52(2):65-71.

21. Bile KM, Hafeez A. Crisis in the Swat Valley of Pakistan: need for international action. Lancet. 2009;374(9683):23. https://doi.org/10.1016/ S0140-6736(09)61226-5.

22. Dean AG, Sullivan KM, Soe MM. OpenEpi: Open Source Epidemiologic Statistics for Public Health, Version. 2013 [updated 06/04/2013. Available from: www.OpenEpi.com. Accessed 24 Dec 2015.

23. Sheehan DV, Lecrubier $Y$, Sheehan $\mathrm{KH}$, Amorim $\mathrm{P}$, Janavs J, Weiller $\mathrm{E}$, et al. The Mini-International Neuropsychiatric Interview (M.I.N.I.): the development and validation of a structured diagnostic psychiatric interview for DSM-IV and ICD-10. J Clin Psychiatry. 1998;59(Suppl 20):22-33 quiz 4-57.

24. Amr MA-M, Hussein Balaha MHH. Minor psychiatric morbidity in young saudi mothers using MINI international neuropsychiatric interview (MINI). J Coll Physicians Surgeons Pak. 2010;20(10):680-4

25. Chen TH, Chang SP, Tsai CF, Juang KD. Prevalence of depressive and anxiety disorders in an assisted reproductive technique clinic. Hum Reprod. 2004; 19(10):2313-8. https://doi.org/10.1093/humrep/deh414.

26. Rutstein SO. Factors associated with trends in infant and child mortality in developing countries during the 1990s. Bull World Health Organ. 2000; 78(10):1256-70.

27. WHO. BMI classification 2006. Available from: http://www assessmentpsychology.com/icbmi.htm. [updated 17/11/2006; cited 2018 9th October]

28. Mason JB, Hunt J, Parker D, Jonsson U. Improving child nutrition in Asia Toronto: The United Nations University; 2001. Contract No.: 3 (supplement).

29. Rondó PH, Ferreira RF, Nogueira F, Ribeiro M, Lobert H, Artes R. Maternal psychological stress and distress as predictors of low birth weight, prematurity and intrauterine growth retardation. Eur J Clin Nutr. 2003;57(2):266.

30. Seng J, Low L, Sperlich M, Ronis D, Liberzon I. Post-traumatic stress disorder, child abuse history, birthweight and gestational age:a prospective cohort study.[internet]. BJOG. 2011;118:1329-39.

31. Imtiaz A, UI Haq Z, Badrashi M, Farooq S. Association of teenage pregnancy with low birth weight: tertiary care hospitals based case control study in Peshawar. Khyber Med Univ J. 2015;7(4):165-73.

32. lacobelli S, Robillard PY, Gouyon JB, Hulsey TC, Barau G, Bonsante F. Obstetric and neonatal outcomes of adolescent primiparous singleton pregnancies: a cohort study in the south of Reunion Island, Indian Ocean. J Matern Fetal Neonatal Med. 2012, Dec;25(12):2591-6. https://doi.org/10. 3109/14767058.2012.718003

33. Zhu BP, Le T. Effect of interpregnancy interval on infant low birth weight: a retrospective cohort study using the Michigan maternally linked birth database. Matern Child Health J. 2003;7(3):169-78. 
34. Yesuf A, Enquoselassie F, Hagos S, Assefa M. Effect of Interpregnancy interval on Low birth weight in Gondar and Bahir Dar referral hospital: a case control study from north West Ethiopia. [internet] J Health Med Nurs. 2016:31:1-9.

35. Bhatti A, Naz S, Majid E, Bhatti N. Maternal risk factors associated with low birth weight babies. Med Channel. 2010;16(2):334-8.

36. Muhammad T, Khattak AA, Khan MA, Khan A, Khan MA. Maternal factors associated with intrauterine growth restriction. J Ayub Med Coll Abbottabad. 2010;22(4):64-69.

37. Siza JE. Risk factors associated with low birth weight of neonates among pregnant women attending a referral hospital in northern Tanzania. Tanzan J Health Res. 2008;10(1):1-8.

38. Mumbare S, Maindarkar G, Darade R, Yenge S, Tolani MK, Patole K. Maternal risk factors associated with term Low Birth Weight Neonates: A matchedpair case control study. Indian Pediatr. 2012;16:49.

39. Xiong XU, Harville EW, Mattison DR, Kelkind-Hirsch K, Pridjian G, Buekens P. Exposure to hurricane Katrina, post-traumatic stress disorder and birth outcomes. Am J Med Sci. 2008;336(2):111-5.

40. Rosen D, Seng JS, Tolman RM, Malinger G. Intimate Partner Violence, depression, and Posttraumatic Stress Disorder as additional predictors of Low Birth Weight infants among low-income mothers. J Interpers Violence. 2007:22(10):1305-14. https://doi.org/10.1177/0886260507304551.

\section{Publisher's Note}

Springer Nature remains neutral with regard to jurisdictional claims in published maps and institutional affiliations.

Ready to submit your research? Choose BMC and benefit from:

- fast, convenient online submission

- thorough peer review by experienced researchers in your field

- rapid publication on acceptance

- support for research data, including large and complex data types

- gold Open Access which fosters wider collaboration and increased citations

- maximum visibility for your research: over $100 \mathrm{M}$ website views per year

At BMC, research is always in progress.

Learn more biomedcentral.com/submissions 